\title{
The Strategic Entry Behavior Choices of Firms under Minimum Quality Standard*
}

\author{
Huishuang He \\ Management and Economic College, North China University of Water Resources and Electric Power, \\ Zhengzhou, China \\ Email: 346952523@qq.com
}

Received 30 September 2014; revised 1 November 2014; accepted 20 November 2014

Copyright (C) 2014 by author and Scientific Research Publishing Inc.

This work is licensed under the Creative Commons Attribution International License (CC BY).

http://creativecommons.org/licenses/by/4.0/

(c) (i) Open Access

\begin{abstract}
In order to analyze the strategic entry behavior choices of firms under minimum quality standard, a basic model is made under the endogenous minimum quality standard. An industry's competitiveness and the level of performance tend to be subject to the entry conditions and the ease of entry. For entrants, the basic entry technological constraint is the minimum quality standard. In differentiated products markets, when there is no minimum quality standard and the entry cost is small, the entrant' profit is the same, whether they choose the high quality or low quality to enter the product market. While in the case of endogenous minimum quality standard, the incumbent may choose to produce low quality products, and the entrant may choose to produce high quality products, which lead to the lack of competition in product markets. Therefore, government should create an open and competitive market environment and efficient policy guidance for firms.
\end{abstract}

\section{Keywords}

Minimum Quality Standard, Entry Deterrence, Product Differentiation

\section{Introduction}

The industry's competitiveness and performance level tend to be affected by entry condition and the degree of ease. Whether a firm can enter the market freely is a main factor to estimate the competitiveness of an industry. The absolute cost advantage of incumbent and product differentiation, economies of scale as well as the government regulations are considered to be the main reasons causing the barrier to entry. In addition to this natural entry barrier, these incumbents' strategic behaviors towards to entrants are another barrier to enter a company or industry. As to the entrant, a fundamental technical factor barrier to entering a company is minimum quality

*This paper is a stage result of Henan Philosophy and Social Science Planning Project (No. 2014CJJ054). 
standard (MQS). The potential and factual entry will affect the behavior of incumbent and optimize the market behavior. The introduction of minimum quality is also a policy to protect the consumers' interests, the consumers' externality and social welfare. Why do we set the minimum quality standards? What are the differences between these entry strategic choices the companies would choose in the free access (no minimum quality standards) and those under the regulation of government (under the minimum quality standards)? Which are all the basic questions that can not be avoided when discuss the quality standards regulations. In this study, we are to solve this problem, in the free entry and under the government's quality regulation, in order to maintain the market power and to ensure higher ability of profits, what impacts would the incumbents have on the decisions' of these potential entrants and market performances. This analysis has significant reference and value of application when we solve the disorderly competition of firms in reality and the minimum quality standards regulation of the government. A general description on related reference is displayed in part 2, and a basic model and its equilibrium analysis about price, quality, profit and welfare are displayed in part 3 , and the basic occlusions and the relevant policy implications are showed in part 4.

\section{General Description on Related Reference}

The existing studies about firms' entry strategic behaviors mainly focus on the entry deterrence theory. The strategies of firms' entry-deterrence can be divided into three parts: strike (Bonnisseau \& Lahmandi-Ayed (2006)), signaling (Donnenfeld \& Weber (1995)) and predatory behavior (Dixit (1979)) [1]-[3]. This kind of Game theory study is about an important issue: when do incumbents prevent entrants through credible strategies in the market. Under this perspective, Equilibrium only exists in the incredible threats which exclude the terrible consequences. The initial literature mainly focused on firms of the same quality, but after the introduction of the conception of differentiation, the entry-deterrence theory made a great improvement. In the industry of differentiated products, firms can prevent entry by pricing strategy but also can compete by product differentiation. In many industries, owing to inseparability of the fixed cost, firms choose effective measures to prevent entry, such as investing in building the most efficient plants, choosing products centrally in limited products sets, selecting the sites in a collective of bounded geographic locations and so on, then if the companies can take the first action in limited space, they can get the first-move advantage in competition, leading to potential entrants have no profit (Schmalensee (1978)) [4]. No matter which kind of analysis and conclusion, which is often extend from the competition of an incumbent and an entrant, considering more about the game behavior between the incumbent and the entrant. No matter which kind of entry deterrence strategy it is, the analysis of conclusions always are based on some basic assumption: firstly, for any incumbent, one way to get profit is to get and maintain monopolistic power, which needs the incumbent preventing entry or acquisition, threatening, repulsion of competitor or maintaining profits by Cartel behavior; Next, the monopolistic power always has backwards effects on efficiency and distribution, which proves the reasonableness and the necessity of antitrust or other legal measures of government intervention from another point of view.

Based on the above research hypothesis and conclusions and combined with the government regulations, this article introduces the strategic entry behavior choices under the minimum quality standard. There are many literatures about the exogenous minimum quality standards (Pezzino (2006), Garella (2006), Ecchia \& Lambertini (2013), Nagurney \& Li (2014)) [5]-[8]. In order to distinct with them, we assume the existence of minimum quality standard which is internalized (social planers belong to the members of the largest social welfare, the minimum quality standard are the internalized quality choice behavior. Seeing Cesi (2010) [9], we analyze game behavior choices of the incumbent and entrant and provide reference for the government making the regulations of the minimum quality standard.

\section{The Basic Model}

Assuming that there is a group of consumers in market, with 1 representing it and $\theta$ representing the consumers' tastes, in which, $\theta \in[\underline{\theta}, \bar{\theta}]$ and $\underline{\theta}=\bar{\theta}-1$. The distribution function is $F(\theta)$, the density function is $f(\theta)$, the consumers $\theta$ only have the unit demand for products. Same with Mussa \& Rosen (1978) [10], we define consumers' utility function as $U=\theta s_{i}-p_{i}, s_{i}$ is the quality of products, and $s_{i} \in[0,1], 1$ is the highest quality, 0 is the lowest quality. $p_{i}$ is the price of the products, the consumers' reservation utility is 0 , that is to say, they choose not to buy in the case of the obtained effect is less than zero when buying products. There are two enterprises, firm 1 and firm $2 \quad(i=1,2)$, and provided that 1 is the incumbent and 2 is the potential en- 
trant. The quality-improved cost is changeable cost, $C_{i}=s_{i}^{2} q_{i}$ (here, $q_{i}$ is the need of products when the quality is $s_{i}$ ). The game can be divided into three stages, the firm 1 choose $s_{1}$ on the first stage, the firm 2 will make the decision whether choose to enter after observing the choice of firm 1 on the second stage. If the firm 2 make the entry decision, entry cost $f$ will be produced because of the entry, Bertrand competition will arise if the entrants enter the market at the same quality, leading to no profit. Therefore, in the equilibrium, the differentiated quality the firm 2 choose is $s_{2} \neq s_{1}$. On the third stage, if the firm 2 choose to enter on the second stage, firm 1 and firm 2 will compete on price in the given quality, otherwise, firm 1 would become a monopolist on the third stage. We use the subgame perfect equilibrium under Bertrand competition if firm 2 enter. On the second stage, if firm 2 enter, fixed cost of entry will exist, and we assume that the firm 2 can choose any level of quality. So the incumbent does not have to produce fixed cost (the fixed cost is sunk cost) and has the cost advantage over the entrant when firm 2 enter the market.

\subsection{Strategic Behavior under Free Entry}

In the case of entry, owing to the entrant taking the same quality as that the incumbent had taken, the Bertrand competition would be aroused, leading to that the profit is 0 . If the entrant chooses to produce product of different quality, thus there are two kinds of quality in market.

Now assuming that $s_{2}\left(s_{1}\right)$ is the firm 2's optimal entry reaction when firm 1 takes quality of $s_{1}$.

$s_{1}^{h}>s_{2}\left(s_{1}^{h}\right), \quad s_{1}^{l}<s_{2}\left(s_{1}^{l}\right)^{2}$ at any time. Firstly, we can figure out the duopoly market equilibrium, and get the recreation function of firm 1 and firm 2 . In a covered duopoly market, the profits of the highest quality firm and the lowest quality firm are:

$$
\begin{aligned}
& \pi_{h}=\left(p_{h}-s_{h}^{2}\right)\left(\bar{\theta}-\frac{p_{h}-p_{l}}{s_{h}-s_{l}}\right) \\
& \pi_{l}=\left(p_{l}-s_{l}^{2}\right)\left(\frac{p_{h}-p_{l}}{s_{h}-s_{l}}-\underline{\theta}\right)
\end{aligned}
$$

On a given product quality level, firms choose their own price, we figure out the Nash equilibrium prices:

$$
\begin{aligned}
& p_{h}^{*}=\frac{1}{3}\left\{\left(s_{l}^{2}+2 s_{h}^{2}\right)+(1+\bar{\theta})\left(s_{h}-s_{l}\right)\right\} \\
& p_{l}^{*}=\frac{1}{3}\left\{\left(2 s_{l}^{2}+s_{h}^{2}\right)+(2-\bar{\theta})\left(s_{h}-s_{l}\right)\right\}
\end{aligned}
$$

The corresponding equilibrium profits are:

$$
\begin{aligned}
& \pi_{h}^{*}=\frac{1}{9}\left(s_{h}-s_{l}\right)\left\{-\left(s_{h}+s_{l}\right)+(1+\bar{\theta})\right\}^{2} \\
& \pi_{l}^{*}=\frac{1}{9}\left(s_{h}-s_{l}\right)\left\{\left(s_{h}+s_{l}\right)+(2-\bar{\theta})\right\}^{2}
\end{aligned}
$$

To ensure that this market is completely covered, the needs of both firms' products are positive and we can calculate the reaction function of the corresponding high quality firm and the low quality firm. The high quality firm's reaction function to the low quality firm is $s_{h}=\frac{s_{l}+\bar{\theta}+1}{3}$, the low quality firm's reaction function to the high quality firm is $s_{l}=\frac{s_{h}+\bar{\theta}-2}{3}$.

\subsubsection{The Analysis about Game Behavior of the Incumbent and the Entrant}

1) The incumbent is a high-quality firm

When the incumbent is a high-quality firm, firm 2 can only choose to enter the market at low price as an entrant. High-quality incumbent would face the choice question on the first stage: 


$$
\begin{aligned}
& \max _{s_{1 h}} \pi_{1 h}=\left(p_{1 h}-s_{1 h}^{2}\right)\left(\bar{\theta}-\frac{p_{1 h}-p_{2 l}}{s_{1 h}-s_{2 l}}\right) \\
& \text { s.t. } \quad s_{2 l}=\frac{s_{1 h}+\bar{\theta}-2}{3}
\end{aligned}
$$

Therefore we can figure out the quality equilibrium is $s_{1 h}^{*}=\frac{2 \bar{\theta}-1}{4}, s_{2 l}^{*}=\frac{2 \bar{\theta}-3}{4}$, the profit equilibrium is $\pi_{1 h}^{*}=\frac{2}{9}, \quad \pi_{2 l}^{*}=\frac{1}{18}-f$ (firm 2 has to pay the fixed cost $f$ as the entrant). The condition of complete covered market is $\bar{\theta} \geq 2.2138$. So it follows that only if $\pi_{2 l}^{*}=\frac{1}{18}-f>0$, firm 2 would consider entering, that is to say, the condition of accommodation to entry is $f<\frac{1}{18}$.

In addition, the profit function of firm 2 is $\pi_{2 l}=\pi_{l}^{*}-f=\frac{1}{9}\left(s_{1 h}-s_{2 l}\right)\left\{\left(s_{1 h}+s_{2 l}\right)+(2-\bar{\theta})\right\}^{2}-f$. When $\pi_{2 l}=0$, the quality of firm 1 is $s_{1 h}^{d}=\frac{\bar{\theta}}{2}-1+\left(\frac{3}{2}\right)^{\frac{5}{3}} f^{\frac{1}{3}}\left(s_{1 h}^{d}\right.$ is the lowest critical quality level that firm 1 can prevent firm 2 to enter, the subscript letter $1 \mathrm{~h}$ is the circumstance of high quality of firm 1). As for $\frac{\partial \pi_{2 l}}{\partial s_{1 h}}>0$, so as long as $s_{1 h}>s_{1 h}^{d}$, firm 2 will enter.

2) The incumbent is a low-quality firm

When the incumbent firm 1 is a low-quality firm, firm 2 choose to enter at low quality. firm 1 would face the choice question on the first stage

$$
\begin{aligned}
& \max _{s_{1 l}} \pi_{1 l}=\left(p_{1 l}-s_{1 l}^{2}\right)\left(\frac{p_{2 h}-p_{1 l}}{s_{2 h}-s_{1 l}}-\underline{\theta}\right) \\
& \text { s.t. } \quad s_{2 h}=\frac{s_{1 l}+\bar{\theta}+1}{3}
\end{aligned}
$$

The quality equilibrium is $s_{1 l}^{*}=\frac{2 \bar{\theta}-1}{4}, s_{2 h}^{*}=\frac{2 \bar{\theta}+1}{4}$, Here, we should ensure the condition that the product is offered to the lowest income consumer is $\theta \geq 2.2583$. The profit equilibrium is $\pi_{1 l}^{*}=\frac{2}{9}, \pi_{2 h}^{*}=\frac{1}{18}-f$.

Thus when $\pi_{2 h}=\frac{1}{18}-f>0$, firm 2 would enter on the second stage. When firm 2 is a high-quality firm and firm 1 is a low-quality firm, the equilibrium quality is $s_{1 l}^{*}=\frac{2 \bar{\theta}-1}{4}, s_{2 h}^{*}=\frac{2 \bar{\theta}+1}{4}$, the equilibrium profit is $\pi_{1 l}^{*}=\frac{2}{9}, \pi_{2 h}^{*}=\frac{1}{18}-f$.

When firm 2 enter the market, the profit function is $\pi_{2 h}=\pi_{h}^{*}-f=\frac{1}{9}\left(s_{2 h}-s_{1 l}\right)\left\{-\left(s_{2 h}+s_{1 l}\right)+(1+\bar{\theta})\right\}^{2}-f$. We put $s_{2 h}=\frac{s_{1 l}+\bar{\theta}+1}{3}$ into the profit function and get the conclusion that when $\pi_{2 h}=\frac{1}{9}\left(\frac{s_{1 l}+\bar{\theta}+1}{3}-s_{l}\right)\left\{-\left(\frac{s_{1 l}+\bar{\theta}+1}{3}+s_{1 l}\right)+1+\bar{\theta}\right\}^{2}-f=-\frac{4}{9}\left(\frac{2 s_{1 l}-\bar{\theta}-1}{3}\right)^{3}-f=0$, firm 1's quality choice 
is $s_{1 l}^{d}=\frac{\bar{\theta}+1}{2}-\left(\frac{3}{2}\right)^{\frac{5}{3}} f^{\frac{1}{3}}$. Because of $\frac{\partial \pi_{2 h}}{\partial s_{1 l}}<0$, as long as $s_{1 l}<s_{1 l}^{d}$, the entry of firm 2 is possible.

3) The entry-deterrence strategy of firm 1

To ensure the market is completely covered and simplify the analysis, we consider the condition of $\bar{\theta} \geq 3$.

I) Low fixed cost and accommodation of the entry. When entry cost is low enough, $f<\frac{1}{18}$, firm 1 will take accommodation strategy and proceed with Stackelberg leadership game in quality. No matter firm 1 is a lowquality firm or high-quality firm, it can always get the profit of $\frac{2}{9}$.

II) High fixed cost and the entry deterrence. If $f$ is large enough, so that even the incumbent choose monopoly quality, the potential entrant could not obtain positive profit. Under this circumstance, entry is deterred, choice of the incumbent is not constrained by the threat of entry. From the above analysis, the quality level range of the incumbent's free choice is $s_{1}^{d} \in\left[s_{11}^{d}, s_{1 h}^{d}\right]$, i.e. $s_{1} \in\left[\frac{\bar{\theta}+1}{2}-\left(\frac{3}{2}\right)^{\frac{5}{3}} f^{\frac{1}{3}}, \frac{\bar{\theta}}{2}-1+\left(\frac{3}{2}\right)^{\frac{5}{3}} f^{\frac{1}{3}}\right]$, the quality choice of monopolist without entry is $s^{*}=\frac{\theta}{2}=\frac{\bar{\theta}-1}{2} \geq s_{1 l}^{d}$, when $f \geq\left(\frac{2}{3}\right)^{5}$.

III) Moderate fixed cost and entry deterrence. When $f<\left(\frac{2}{3}\right)^{5}$, entry cost is not big enough to stop from entering, there would be two options for the incumbent: to accommodate entry or block entry with the quality choice of $s_{1}^{d}$.

When $f=\frac{1}{18}$, if entry is accommodated, the incumbent can get the highest profit from accommodating entry is $\lim _{s_{1}} \pi_{1}^{a}\left(s_{1}, s_{2}\left(s_{1}\right)\right)=\frac{2}{9}$, (the superscript $a$ means accommodation situation). When the profit is $\frac{2}{9}$, the incumbent could choose quality $s_{1}^{a}=\frac{2 \bar{\theta}-1}{4}$, the profit entrant could get is zero, the entry is deterred. The condition of the market is covered is $\bar{\theta} \geq \frac{7}{2}$, and the incumbent get the profit $\pi_{1}^{a^{*}}=\frac{(2 \bar{\theta}-3)(2 \bar{\theta}-1)}{16}>\frac{2}{9}$. So when $f=\frac{1}{18}$, the entry is deterred, the quality of the incumbent is $s_{1}^{a}=\frac{2 \bar{\theta}-1}{4}$, the price of the incumbent is $p_{1}^{a}=\frac{2 \bar{\theta}^{2}-3 \bar{\theta}+1}{4}$, the profit of the incumbent is $\pi_{1}^{a^{*}}=\frac{(2 \bar{\theta}-3)(2 \bar{\theta}-1)}{16}$.

When $\frac{1}{18}<f<\left(\frac{2}{3}\right)^{5}$, entry cost is relatively high and not be so high that the entry is deterred, the optimal quality choice under monopoly condition is $\frac{\partial \pi_{1}}{\partial s_{1}}=\underline{\theta}-2 s_{1}=0$. When $s_{1}<\frac{\underline{\theta}}{2}, \frac{\partial \pi_{1}}{\partial s_{1}}>0$, the profit $\pi_{1}$ increases with the increase of $s_{1}$; When $s_{1}>\frac{\theta}{2}, \frac{\partial \pi_{1}}{\partial s_{1}}<0$, the profit $\pi_{1}$ decreases with the increase of $s_{1}$. Because under the condition of entry deterrence, incumbents quality choice collection is

$s_{1}^{d} \in\left[\frac{\bar{\theta}+1}{2}-\left(\frac{3}{2}\right)^{\frac{5}{3}} f^{\frac{1}{3}}, \frac{\bar{\theta}}{2}-1+\left(\frac{3}{2}\right)^{\frac{5}{3}} f^{\frac{1}{3}}\right]>\frac{\theta}{2}$, so when $\frac{1}{18}<f<\left(\frac{2}{3}\right)^{5}$, the optimal quality choice of the incum- 
bent's entry deterrence is $s_{1 d}^{*}=s_{1 l}^{d}=\frac{\bar{\theta}+1}{2}-\left(\frac{3}{2}\right)^{\frac{5}{3}} f^{\frac{1}{3}}$, and the incumbent enter the market at low quality and the profit gained under market coverage is $\pi_{1 d}^{*}=\underline{\theta} s_{1 d}^{*}-\left(s_{1 d}^{*}\right)^{2}$. So when $\frac{1}{18}<f<\left(\frac{2}{3}\right)^{5}$, the entry deterrence strategy of the incumbent is $s_{1 d}=s_{1 l}^{d}=\frac{\bar{\theta}+1}{2}-\left(\frac{3}{2}\right)^{\frac{5}{3}} f^{\frac{1}{3}}$, the monopoly profit gained is $\pi_{1 d}^{*}=\underline{\theta} s_{1 d}^{*}-\left(s_{1 d}^{*}\right)^{2}=\left(\frac{\bar{\theta}+1}{2}-\left(\frac{3}{2}\right)^{\frac{5}{3}} f^{\frac{1}{3}}\right)\left(\frac{\bar{\theta}}{2}-2+\left(\frac{3}{2}\right)^{\frac{5}{3}} f^{\frac{1}{3}}\right)$.

\subsubsection{The Analysis about Consumers' Surplus and Social Welfare}

1) Analysis about consumers' surplus

I) Under the high entry cost $f \geq\left(\frac{2}{3}\right)^{5}$ without entry, the consumers surplus is $c s_{1}^{*}=\frac{\bar{\theta}-1}{4}$.

II) Under accommodation of entry when $f<\frac{1}{18}$, consumers' surplus is

$C S=\int_{\theta_{h l}}^{\bar{\theta}}\left(\theta s_{h}-p_{h}\right) \mathrm{d} \theta+\int_{\underline{\theta}}^{\theta_{h l}}\left(\theta s_{l}-p_{l}\right) \mathrm{d} \theta$, we put $s_{1 h}^{*}=\frac{2 \bar{\theta}-1}{4}, \quad s_{2 l}^{*}=\frac{2 \bar{\theta}-3}{4}$ and $s_{1 l}^{*}=\frac{2 \bar{\theta}-1}{4}, s_{2 h}^{*}=\frac{2 \bar{\theta}+1}{4}$ into it and get consumers surplus which is $c s_{1 h 2 l}^{*}=c s_{12 h}^{*}=\frac{36 \bar{\theta}^{2}-36 \bar{\theta}-35}{144}$.

III) When $f=\frac{1}{18}$, consumers' surplus is $c s=\int_{\underline{\theta}}^{\bar{\theta}}(\theta s-p) \mathrm{d} \theta$, we put $s_{1}^{a}=\frac{2 \bar{\theta}-1}{4}, \quad p_{1}^{a}=\frac{2 \bar{\theta}^{2}-3 \bar{\theta}+1}{4}$ into it and get consumers surplus which is $\mathrm{Cs}_{1}^{a^{*}}=\frac{2 \bar{\theta}-1}{8}$

2) Analysis on social welfare

I) Under the high entry cost $f \geq\left(\frac{2}{3}\right)^{5}$ without entry, the social welfare is $w_{1}^{*}=\frac{\bar{\theta}^{2}-\bar{\theta}}{4}$.

II) Under accommodation of entry when $f<\frac{1}{18}$, the social welfare is

$w=\int_{\theta_{h l}}^{\bar{\theta}}\left(\theta s_{h}-s_{h}^{2}\right) \mathrm{d} \theta+\int_{\underline{\theta}}^{\theta_{h l}}\left(\theta s_{l}-s_{l}^{2}\right) \mathrm{d} \theta-f$. We put $s_{1 h}^{*}=\frac{2 \bar{\theta}-1}{4}, \quad s_{2 l}^{*}=\frac{2 \bar{\theta}-3}{4}$ and $s_{1 l}^{*}=\frac{2 \bar{\theta}-1}{4}$,

$s_{2 h}^{*}=\frac{2 \bar{\theta}+1}{4}$ into it, and get the social welfare which is $w_{1 h 2 l}^{*}=w_{112 h}^{*}=\frac{36 \bar{\theta}^{2}-36 \bar{\theta}+5}{144}-f$.

III) When $f=\frac{1}{18}$, the social welfare is $w_{1}^{a}=\int_{\underline{\theta}}^{\bar{\theta}}\left(\theta s_{1}-s_{1}^{2}\right) \mathrm{d} \theta$, we put $s_{1}^{a}=\frac{2 \bar{\theta}-1}{4}$ into it and get the social welfare which is $w_{1}^{a^{*}}=\frac{(2 \bar{\theta}-1)^{2}}{4}$.

IV) Under entry deterrence when $\frac{1}{18}<f<\left(\frac{2}{3}\right)^{5}$, the social welfare is $w_{1 d}=\int_{\underline{\theta}}^{\bar{\theta}}\left(\theta s_{1}-s_{1}^{2}\right) \mathrm{d} \theta$, we put $s_{1}=s_{1 d}^{*}$ into it and get social welfare which is $w_{1 d}^{*}=s_{1 d}^{*}\left(\bar{\theta}-\frac{1}{2}-s_{1 d}^{*}\right)=\frac{\bar{\theta}^{2}}{4}-\frac{\bar{\theta}}{4}-\frac{1}{2}+\left(\frac{3}{2}-\frac{\bar{\theta}}{4}\right)\left(\frac{3}{2}\right)^{\frac{5}{3}} f^{\frac{1}{3}}-\left(\left(\frac{3}{2}\right)^{\frac{5}{3}} f^{\frac{1}{3}}\right)^{2}$. 


\subsection{The Strategic Entry Behavior of the Entrant and the Incumbent under Minimum Quality Standard}

\subsubsection{The Incumbent Is a High-Quality Firm}

Government choose the minimum quality standard to maximize social welfare and the incumbent is constrained by the minimum quality standard. That is to say, government sets the minimum quality standard considering incumbent's optimal response. Incumbent's profit maximizing problem is

$$
\begin{aligned}
& \max _{s_{1}} \pi_{1}=\pi_{h}^{*}=\frac{1}{9}\left(s_{h}-s_{l}\right)\left\{-\left(s_{h}+s_{l}\right)+(1+\bar{\theta})\right\}^{2} \\
& \text { s.t. } \frac{\partial \mathrm{w}}{\partial s_{2}}=\frac{\partial\left(\int_{\theta_{12}}^{\bar{\theta}}\left(\theta s_{1}-s_{1}^{2}\right) \mathrm{d} \theta+\int_{\underline{\theta}}^{\theta_{12}}\left(\theta s_{2}-s_{2}^{2}\right) \mathrm{d} \theta\right)}{\partial s_{2}}=0
\end{aligned}
$$

We calculate (2-9) and get $\frac{\partial \mathrm{w}}{\partial s_{2}}=\frac{5 s_{1}^{2}-15 s_{2}^{2}-28 s_{2}-10 s_{1} s_{2}+20 \bar{\theta} s_{2}-5 \bar{\theta}^{2}+14 \bar{\theta}-8}{18}=0$, further figure it out $s_{2}=\frac{10 \bar{\theta}-5 s_{1}-14 \pm \sqrt{100 s_{1}^{2}+140 s_{1}-100 \bar{\theta} s_{1}+25 \bar{\theta}^{2}-70 \bar{\theta}+76}}{15}$. It is easy to prove that regulator's optimal reaction function is to obtain the biggest of the two, we put the maximum value into incumbent's optimal reaction function and get $s_{1 h}^{q}=\frac{\bar{\theta}}{2}+0.068811, s_{2 l}^{q}=\frac{\bar{\theta}}{2}-0.337644$ (superscript $q$ indicates optimal recreation with the presence of minimum quality standard).

Note $s_{2 l}^{q}>s_{2 l}^{*}$, so minimum quality standard affects choice of the low-quality firm. The condition that market is covered is $\bar{\theta} \geq 2.0206$, the equilibrium quality option is acceptable. The profit is $\pi_{1 h}^{q}=0.072662$,

$\pi_{2 l}^{q}=0.135004-f$, consumers surplus is $c s_{1 h 2 l}^{q}=\frac{\bar{\theta}(\bar{\theta}-1)}{4}-0.142898$, social welfare is

$w_{1 h 2 l}^{q}=0.064768+\frac{\bar{\theta}(\bar{\theta}-1)}{4}-f$.

Thus we draw these conclusions that the incumbent' entry deterrence choices are as follows.

1) Low fixed cost and accommodation of entry. Under minimum quality standard, when firm 1 is a high-quality firm and $f<0.135004$, firm 1 will accommodate the entry of firm 2 and get the profit of $\pi_{1 h}^{q}=0.072662$.

2) High fixed cost and entry deterrence. Firstly, when $f=0.135004$, and the incumbent accommodate entry under the minimum quality standard, the incumbent can take quality choice, $s_{1 h}^{q}=\frac{\bar{\theta}}{2}+0.068811$, which can make it get the maximum profit $\pi_{1 h}^{q}=0.072662$. However, when $s_{1 h}^{q}=\frac{\bar{\theta}}{2}+0.068811$, the entrant can get profit of zero and the incumbent would monopolize the market and get the profit

$\pi_{1 h}^{q m}=(\bar{\theta}-1) s_{1 h}^{q}-\left(s_{1 h}^{q}\right)^{2}=\frac{\bar{\theta}^{2}}{4}-\frac{\bar{\theta}}{2}-0.073545$. It is easy to prove $\pi_{1 h}^{q m}>\pi_{1 h}^{q}$, so when $f=0.135004$, firm 2 choose not to enter, while firm 1 choose $s_{1 h}^{q m}=\frac{\bar{\theta}}{2}+0.068811$ under the constraint of minimum quality standard, the price is $p_{1 h}^{q m}=\frac{\bar{\theta}^{2}}{2}-0.431189 \bar{\theta}-0.068811$ and firm 1get monopoly profit of covered market which is $\pi_{1 h}^{q m}=\frac{\bar{\theta}^{2}}{4}-\frac{\bar{\theta}}{2}-0.073545(\bar{\theta} \geq 2.137622$ under covered market), the consumers surplus is $C S_{1 h}^{q m}=\frac{\bar{\theta}^{2}}{2}+0.387622 \bar{\theta}+0.043875$, the social welfare is $w_{1 h}^{q m}=\frac{3 \bar{\theta}^{2}}{4}-0.112378 \bar{\theta}-0.02967$. Secondly, when $f>0.135004$, the incumbent's monopoly choice of quality that can prevent entry is $s_{1}<s_{1 h}^{d}$ i.e. 
$s_{1}<\frac{\bar{\theta}}{2}-1+\left(\frac{3}{2}\right)^{\frac{5}{3}} f^{\frac{1}{3}}$. While monopolist monopoly choice of quality is

$s_{1}=\frac{\bar{\theta}-1}{2}<\frac{\bar{\theta}}{2}-0.337644<\frac{\bar{\theta}}{2}-1+\left(\frac{3}{2}\right)^{\frac{5}{3}} f^{\frac{1}{3}}$ without the presence of entry. So when $f>0.135004$, the minimum quality standard is $s_{\min }=\frac{\bar{\theta}}{2}-0.337644$, the incumbent's quality choice of deterring entry is

$s_{1 h}^{q d}=s_{\min }=\frac{\bar{\theta}}{2}-0.337644$, the price is $p_{1 h}^{q d}=\frac{\bar{\theta}^{2}}{2}-0.837644 \bar{\theta}+0.337644$, the profits is

$\pi_{1 h}^{q d}=\frac{\bar{\theta}^{2}}{4}-\frac{\bar{\theta}}{2}+0.22364$ under covered market $(\bar{\theta} \geq 3.324712)$, the consumers surplus is

$C S_{1 h}^{q d}=\frac{\bar{\theta}^{2}}{2}-0.42528 \bar{\theta}+0.059218$, the social welfare is $w_{1 h}^{q d}=\frac{3 \bar{\theta}^{2}}{4}-0.92528 \bar{\theta}+0.282825$.

\subsubsection{The Incumbent Is a Low-Quality Firm}

If the incumbent is a low-quality firm, this equal to that the regulator is a leaders on the stage of quality choice, the leader aims at

$$
\begin{aligned}
& \max _{s_{1}} w=\int_{\theta_{12}}^{\bar{\theta}}\left(\theta s_{2}-s_{2}^{2}\right) \mathrm{d} \theta+\int_{\underline{\theta}}^{\theta_{12}}\left(\theta s_{1}-s_{1}^{2}\right) \mathrm{d} \theta-f \\
& \text { s.t. } \frac{\partial \pi_{2}}{\partial s_{2}}=\frac{\partial \pi_{h}^{*}}{\partial s_{h}}=\frac{3 s_{2}^{2}+2 s_{1} s_{2}-s_{2}^{2}-4 s_{2}(1+\bar{\theta})+\bar{\theta}^{2}+2 \bar{\theta}+1}{9}
\end{aligned}
$$

The solution of $(2-10)$ is $s_{2}=1+\bar{\theta}-s_{1}$ or $s_{2}=\frac{1+\bar{\theta}+s_{1}}{3}$. Considering the complementarity of quality strategies, there are two acceptable solutions. We figure out the optimal solution to the optimal reaction is $s_{1 l}^{q}=\frac{40 \bar{\theta}-65+3 \sqrt{145}}{80}, \quad s_{2 h}^{q}=\frac{40 \bar{\theta}+5-\sqrt{145}}{80}$.

The condition of covered market is $\bar{\theta} \geq 2.22258$, equilibrium profits is $\pi_{1 l}^{q}=0.218755$, $\pi_{2 h}^{q}=0.0840355-f$. The social welfare is $w_{1 / 2 h}^{q}=0.0406608+\frac{\bar{\theta}(\bar{\theta}-1)}{4}-f$. Note that $w_{1 / 2 h}^{q}>w_{12}^{*}$, but $s_{1 l}^{q}<s_{1 l}^{*}$.

Therefore, in the case that the incumbent is a low-quality firm, the setting of social welfare standard is invalid, which does not affect the quality choices of the incumbent and the entrant. But if the incumbent and the entrant reduce quality level, it will be an improvement of social welfare. So in the case that the incumbent is a firm of low-quality product, the analysis is same to that under the entry behavior without quality regulation, the quality standard does not affect the behavior choice of the incumbent and the entrant.

\section{Basic Conclusions and Associated Policy Implications}

\subsection{Basic Conclusions}

1) When there is the minimum quality standard and it is endogenously determined, the equilibrium profit is rather different because the different quality choice of the incumbent and the entrant. When the incumbent is a high-quality firm, the entrant's profit is increased due to that the minimum quality standard limits the range of the entrant's quality choice and the entry's fixed cost is high. Meanwhile, under the minimum quality standard, the range of the incumbent's free quality entry is limited even if the entrant' entry cost is rather high.

2) When the incumbent is a high-quality firm, the minimum quality standard aroused from maximizing social welfare improves consumers' utility and increases social welfare. When the incumbent is a low-quality firm, minimum quality standard does not change the quality choice of the entrant and the incumbent, and their entry behavior are the same to those without the minimum quality standard. But if the incumbent and the entrant re- 
duce the quality level, it would increase social welfare. Therefore, when the incumbent is a high-quality firm, government should set the minimum quality standard to increase social welfare. The government set the minimum quality standard hasn't so much impact on social welfare when the incumbent is low-quality firm.

3) After comparison, without the constraint of the minimum quality standard, and the entry cost is relatively low, the profit of the entrant is the same whether the entrant is low-quality firm or high-quality firm. When the quality standard is internalized, the available quality choices for the incumbent and entrant are limited, the highquality incumbent gets less profit than the low-quality incumbent, and the entrant is the same. Therefore, in the case that entry cost is relative low, the incumbent will choose to produce low-quality product when the incumbent can choose freely.

When quality standards is internalized, because the optimal minimum quality standard that meets social welfare narrows the available quality difference between the incumbent and the entrant, so the incumbent gets less profits when it is a low-quality firm than it is a high-quality firm, while the entrant is the opposite. Therefore, in the case that entry cost is relative low, the entrant will choose to produce low-quality products when it can choose freely.

\subsection{The Relevant Policy Implications}

The motivation of the set of the minimum quality standard is to improve consumers' social welfare by strengthening market competition, thus improve whole social welfare. In the specific social practice, it mainly reflects on quality certification, administrative examination and approval etc. In economic practice, Quality certification mainly plays a role in practicing quality standards, reducing personal injury and property damage, guiding consumers to buy safe and reliable products, improving the competitiveness of products in international market, and as the effective means of eliminating technical barrier to trade, improving the manage level of quality and so on. The minimum quality standard is beneficial to both consumers and firms.

In addition, under perfect competition, firms' entry to some industry will continue until firms get the normal investment profits without any other profits. When there is minimum quality standard and it is internalized, the incumbent may choose to produce low-quality products and the entrant may choose to produce high-quality products to enter the market, which leads to the lack of competition in market. So under sufficient market demand, we should encourage competition in order to create an open and competitive market environment and policy guidance.

The above analysis focused on the minimum quality standard which is internalized. In practical economy, there is also the case of minimum quality standard that is externalized. It is easier to analyze the exogenous quality standard. Because the set of exogenous quality standards provide direct quality choices reference to these incumbents. The former literature has detailed analysis, it is not repeated here.

\section{Note}

This paper's earlier Chinese edition was first published in Technoeconomics \& Management Research, No. 2, 2013, pp. 7-11.

\section{References}

[1] Bonnisseau, J.-M. and Lahmandi-Ayed, R. (2006) Vertical Differentiation: Multiproduct Strategy to Face Entry? Topics in Theoretical Economics, 6, 1282.

[2] Donnenfeld, S. and Weber, S. (1995) Limit Qualities and Entry Deterrence. The RAND Journal of Economics, 26, 113130. http://dx.doi.org/10.2307/2556038

[3] Dixit, A. (1979) A Model of Duopoly Suggesting a Theory of Entry Barriers. The Bell Journal of Economics, 10, $20-32$. http://dx.doi.org/10.2307/3003317

[4] Schmalensee, R. (1978) Entry Deterrence in the Ready-to-Eat Breakfast Cereal Industry. The Bell Journal of Economics, 9, 305-327. http://dx.doi.org/10.2307/3003584

[5] Pezzino, M. (2006) Minimum Quality Standards with More than Two Firms under Cournot Competition. Economics Discussion Paper EDP-0613, The University of Manchester, Manchester.

[6] Garella, P.G. (2006) “Innocuous” Minimum Quality Standards. Economic Letters, 92, 368-374. http://dx.doi.org/10.1016/j.econlet.2006.03.022

[7] Ecchia, G., Lambertini, L. and Tampieri, A. (2013) Minimum Quality Standards in Hedonic Markets with Environ- 
mental Externalities. Environmental Modeling \& Assessment, 18, 319-323. http://dx.doi.org/10.1007/s10666-012-9345-z

[8] Nagurney, A. and Li, D. (2014) Equilibria and Dynamics of Supply Chain Network Competition with Information Asymmetry in Quality and Minimum Quality Standards. Computational Management Science, 11, 285-315. http://dx.doi.org/10.1007/s10287-014-0216-8

[9] Cesi, B. (2010) Mergers under Endogenous Minimum Quality Standard: A Note. Economics Bulletin, 30, $3260-3266$.

[10] Mussa, M. and Rosen, S. (1978) Monopoly and Product Quality. Journal of Economic Theory, 18, 301-317. http://dx.doi.org/10.1016/0022-0531(78)90085-6 
Scientific Research Publishing (SCIRP) is one of the largest Open Access journal publishers. It is currently publishing more than 200 open access, online, peer-reviewed journals covering a wide range of academic disciplines. SCIRP serves the worldwide academic communities and contributes to the progress and application of science with its publication.

Other selected journals from SCIRP are listed as below. Submit your manuscript to us via either submit@scirp.org or Online Submission Portal.
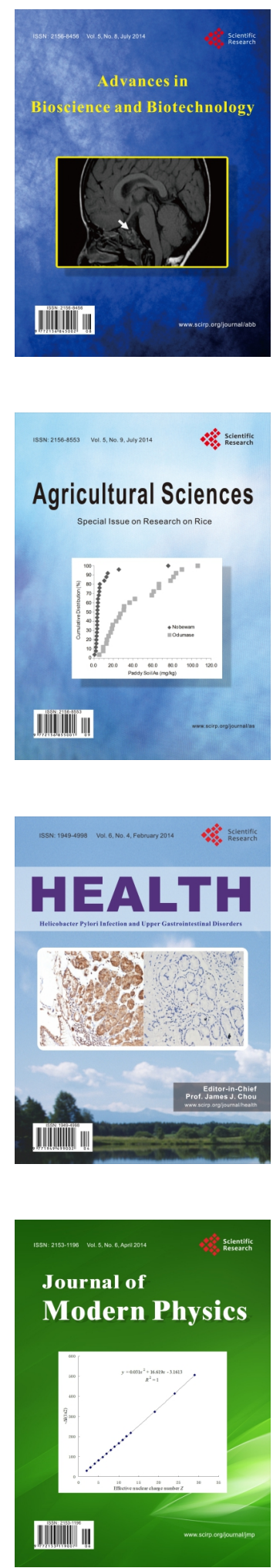
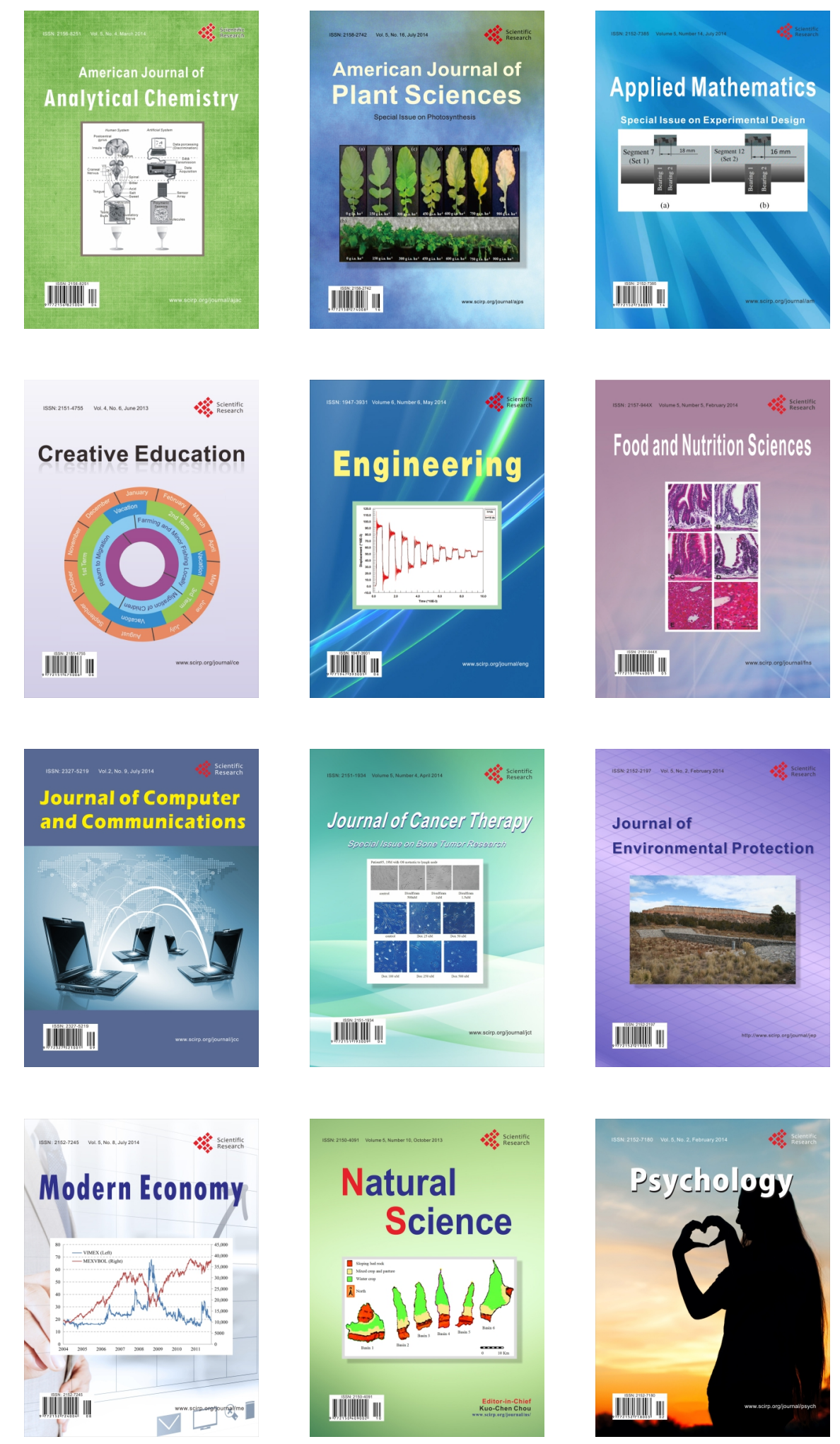